\title{
Neighborhood social capital and sleep duration: a population based cross- sectional study in a rural Japanese town
}

Thida Win ${ }^{1}$, Toru Yamazaki ${ }^{1,2}$, Koji Kanda ${ }^{3}$, Kazuo Tajima ${ }^{1}$ and Shigeru Sokejima ${ }^{1,2^{*}}$

\begin{abstract}
Background: Studies on social capital and health outcomes have become common, but the relationship between neighborhood social capital and sleep duration by gender is still unclear. We examined the relationship between neighborhood social capital and sleep duration by gender in adults living in a rural community in Japan.

Method: We conducted a cross-sectional survey of 12,321 residents aged $\geq 20$ years in a town in Mie Prefecture in January-March 2013. Self-completed questionnaires were collected from the residents ( $n=7782$; valid participation rate, 63.2\%). We used five items to assess the neighborhood social capital (Cronbach's $a=0.86)$. We summed up the scores of each item, and then divided the participants into four groups by quartile of total scores of neighborhood social capital (lowest, low, high, and highest). Sleep duration of $<7 \mathrm{~h} /$ day was defined as insufficient sleep duration according to previous studies. To adjust for potential confounders, we performed a multiple log-binominal regression analysis and estimated the prevalence ratios (PRs) and 95\% confidence intervals (Cls) for insufficient sleep.
\end{abstract}

Results: Overall $42 \%$ of the men and $45 \%$ of the women had insufficient sleep. In the men, the lowest group of neighborhood social capital presented a 22\% higher prevalence of insufficient sleep (PR 1.22; 95\% Cls 1.08-1.38) compared to the highest group of neighborhood social capital. Similarly the low group of neighborhood social capital and the high group of neighborhood social capital had 20 and 19\% higher prevalence of insufficient sleep (PR 1.20; 95\% Cls 1.06-1.36; PR 1.19; $95 \%$ Cls 1.06-1.34, respectively) compared to the highest group of neighborhood social capital. For women there was no significant association between neighborhood social capital and insufficient sleep after controlling for all potential confounders.

Conclusion: Having lower neighborhood social capital was associated with insufficient sleep among Japanese adults, particularly in the men. This suggests that the context of neighborhood social capital by gender should be considered to promote healthier behaviors with regard to getting enough sleep.

Keywords: Neighborhood social capital, Gender, Health behavior, Sleep duration

\section{Background}

Studies on social capital and health outcomes have become much more common, and social capital is considered an important determinant of health [1]. 'Social capital' is defined as "resources composed of or derived from trust, and/or norms (especially reciprocity), and/or networks, which facilitate collective actions" [2]. The resources

\footnotetext{
* Correspondence: sokejima@doc.medic.mie-u.ac.jp

${ }^{1}$ Department of Public Health and Occupational Medicine, Mie University Graduate School of Medicine, 2-174 Edobashi, Tsu-shi, Mie 514-8507, Japan ${ }^{2}$ Epidemiology Centre for Disease Control and Prevention, Mie University Hospital, Tsu, Mie, Japan

Full list of author information is available at the end of the article
}

generated by a community or neighborhood are referred to as "neighborhood social capital" (NSC) [3]. A highly cohesive community is crucial in attempts to promote healthier behaviors. For example, a well-connected neighborhood enables its residents to easily distribute information on health-promoting behaviors [4]. A supportive neighborhood also advocates healthier behaviors through psychosocial or stress coping mechanisms [5]. Moreover, a community with informal social control enhances the maintenance of healthy behavioral norms or the deterrence of risky behaviors among neighbors [6]. 
Several studies have shown that health-related behaviors such as smoking, alcohol drinking, physical activity, and sleep are important mediators between NSC and health outcomes $[3,7,8]$. However few studies described the direct relationship between NSC and sleep disorders $[9,10]$. In addition, NSC differs between the genders in terms of social networks and opportunities to invest in social capital [11]. For instance, Elisabetta Addis and Majlinda Joxhe presented that men and women differ in network structure and accumulation of social capital which is not only reflecting the basic biological sex but also the diverse constructs of behavior, attitude and norms of the society [12]. The gender gap is largely reflected in the way that the day-to-day activities of men and women differ, and studies of social capital should therefore consider the gender differences [13]. Previous studies also showed inconsistent gender differences in the relationship between social capital and health outcomes. For example, a study in Japan showed that the women having stronger bridging social capital were more likely to have the depressive mood but the association was not found in the men [14]. With the greater magnitude for women health than for men, M. Stafford et al. described the presence of gender role in the neighborhood characteristics such as trust, integration into wider society etc. [15]. Conversely, in Russia, men with increased formal and informal social participation reported poorer health than who did not whereas no such significant relationship were found in women [16]. Therefore it is important enough to detect the role of gender in studies of social capital and health outcomes. However, there has been relatively little research into gender differences in NSC and sleep disorders.

Sleep disorders have been a key public health issue. Sleep problems are a major challenge in developed countries, and sleeping disturbances were found in one out of five people in Japan $[17,18]$. For instance, the recommended sleep duration for a normal adult person is 7-9 $\mathrm{h}$ (hrs) according to the U.S. National Sleep Foundation [19]. According to a report by the Organization for Economic Co-operation and Development (OECD), average sleep duration of the OECD countries was $8 \mathrm{~h}$ and $22 \mathrm{~min}(\mathrm{~min})$, but Japan had the second-least average sleep duration (7 $\mathrm{h} 43 \mathrm{~min}$ ) among the OECD countries [20]. Japanese Statistics Bureau also reported that sleeping time in Japan for both sexes was declining over past two decades [21]. Although both short and long sleeping times can cause health problems, several studies reported that short sleep duration was rather related to adverse health outcomes [22-25]. Particularly in Japan, short duration of sleep is the most frequent problem because of long working hours and less sleeping time [26]. The prevalence of short sleeping time in Japanese was ranging from 47.6 to $51.5 \%$ although the definitions of short duration of sleep differed among studies [26-28]. Sleep duration $<7 \mathrm{~h}$ was especially associated with mortality and metabolic risk factors in Japan [25, 28, 29].

Moreover, insufficient sleep induces poor health through several triggering factors [30-32]. For example, sleep disturbances induced by multiple stressors can cause mental illnesses [33, 34]. Socio-environmental factors also have enormous effects on insufficient sleep [35-37]. Gender differences in sleep are also very important because of their different attribution to biological, psychosocial and cultural influences [38]. For example the brain activity of men and women differs before and after sleep [39] and this underlying biological difference is worth to recognize in sleep studies. Moreover Sarah A. Burgard pointed out that women had disproportionate burden of interrupted sleep for caregiving because of differences in social roles and work-family responsibilities than men do [40]. Previous studies suggested that a sleep study in relation to health outcomes should be conducted by genders because there were not any consistent differences in genders across the studies [41, 42]. In addition, gender differences can exist in the relation between sleep and socioenvironmental factors such as neighborhood disadvantages or neighborhood social capital [10, 43]. However, the evidence is limited for the association of NSC in relationship to insufficient sleep in accord with gender. In the present study we thus examined the association between NSC and insufficient sleep by gender in a general population of Japanese adults.

\section{Methods}

\section{Data collection}

We conducted a population-based cross-sectional survey in a rural town located in eastern Mie Prefecture, where a total of 15,280 residents lived at the time of our survey. The survey was conducted in 2013 from January to March using self-completed questionnaire, targeting 12,321 residents aged $\geq 20$ years. The questionnaire asked the respondent about his or her socioeconomic status, lifestyle, sleep hours, work hours, social capital, self-rated health, and non-communicable diseases (NCDs). Of the target population, 7782 residents gave consent to use their information in this study, and the valid participation rate was $63.2 \%$. Of the residents, the respondents who did not answer the age and gender questions $(0.78 \%, n=61)$ were regarded as unreliable and were excluded from the analysis. A final total of 7721 respondents were analyzed. The study protocol was approved by the Ethical Committee of the Medical Department of Mie University, Japan (Approved number: 1268). Written informed consent was obtained from all participants. The study was conducted in accordance with the Helsinki Declaration. 


\section{Measurement of neighborhood social capital (NSC)}

In our study, the definition of NSC involved cognitive and structural dimensions. Neighborhood social capital was assessed by the individual respondent's perception of social capital in his or her neighborhood reflecting the feeling of fellowship, emotional social support, norms of reciprocity, perceived neighborhood trust, and social activity or cooperation. The NSC questionnaire was derived from the questionnaire of Cabinet Office, Government of Japan (COJ), 2003 [44]. The respondents were required to answer the following five items: (1) I feel myself as a member of neighbors (feeling of fellowship). (2) I have someone in my neighborhood to consult when I need to talk to someone (emotional social support). (3) I like someone in my neighborhood who has the same idea as me (reciprocity norm). (4) I think people in my neighborhood trust each other (perceived neighborhood trust). (5) I and my neighbors perform social activities together for the betterment of the neighborhood (social activity or co-operation) [45-48].

These five items were measured on a five-point Likert scale: strongly disagree, disagree, neither, agree, and strongly agree. We summed up the scores of each item on the questionnaire, and then divided the participants into four groups by quartiles of total NSC score, where the 1st quartile was defined as the 'lowest' NSC, the 2nd quartile was defined as the 'low' NSC, the 3rd quartile defined as the 'high' NSC, and the 4th quartile defined as the 'highest' NSC.

\section{Sleeping time}

The participants were asked, 'In the past 1 month, on average, how many hours of actual sleep do you generally get in a day? According to Kripke et al. [49], sleeping times $<2 \mathrm{~h}$ and $>16 \mathrm{~h}(0.35 \%)$ were considered unreliable and invalid. In the present study we thus coded these sleep durations as missing values. Based on our review of relevant studies [8, $19,25,50,51]$, we defined the sleep duration of $7 \mathrm{~h}$ per day as the optimum number of hours of sleep for adults. In accordance with a previous study in Japan [8], we dichotomized the respondents' sleep durations into $\geq 7 \mathrm{~h}$ per day and $<7 \mathrm{~h}$ per day. Insufficient sleep was considered a sleep duration of $<7 \mathrm{~h}$ per day.

\section{Covariates}

We selected the following as potential confounders in our study: age, gender, educational attainment, occupation, annual household income, smoking, alcohol drinking, physical activity, body mass index (BMI), and presence of noncommunicable disease (NCD). Age was grouped into the following four categories: 20-39, 40-59, 60-79, and $\geq 80$ years. Educational attainment was defined as low (elementary school, junior and senior high school), medium (college and vocational schools), and high (university, Master's degree and above). The respondents' occupations were categorized into the following three groups: blue collar, white collar, and others (i.e., housewives and students) [52].

Annual household income was collapsed into five categories: $<2$ million yen, 2-million to less than 4 million yen, 4million to less than 6 million yen, 6-million to less than 8 million yen, and $\geq 8$ million yen [47]. For smoking, the following three groups were created: smoker, ex-smoker and non-smoker. Alcohol drinking was also classified into daily drinker, occasional drinker and non-drinker. With regard to physical activity, $\geq 150$ min per week of physical activity was regarded as physically active, and $<150$ min per week was physically inactive according to the $\mathrm{WHO}$ recommendation for adults [53].

BMI $\left(\mathrm{kg} / \mathrm{m}^{2}\right)$ was also classified by the following WHO recommendation [54]: underweight $(<18.50 \mathrm{BMI})$, normal (18.50-24.99), overweight (25.00-29.99) and obese ( $\geq 30)$. If a respondent reported having any one of the following noncommunicable diseases (NCD) (stroke, hypertension, diabetes mellitus, myocardial infarction, allergy, asthma, and cancer), he or she was considered to have an NCD in this study.

\section{Statistical analysis}

We conducted an internal reliability of NSC questions by using Cronbach's $\alpha$. For the evaluation of a high degree of correlation among independent variables, we used related statistics such as variance inflation factor (VIF) and tolerance value (TOL) [55]. By considering the importance and inconsistent results of gender differences in NSC and sleep disorders from the previous studies [56-58], we carried out a gender-stratified analysis. We calculated frequency distribution to describe the basic characteristics of the participants. Bivariate analysis of the chi-square test for independency and analysis of variances was done to assess the differences in characteristics among NSC groups. We also conducted the interaction tests for socioeconomic factors in the relationship between NSC and insufficient sleep to find the effect modification by adding the interaction term in the log-binomial model. For missing data, the fully conditional specification (FCS) method of the multiple imputation (MI) procedure was used to replace the missing values, and it was performed separately for the men and the women [59].

A total of 10 imputed datasets by gender were created for the analysis. The variables in the imputation model were sleep duration, NSC, age, education, occupation, annual household income, smoking, alcohol drinking, physical activity, BMI and NCD. We performed a multiple regression using log-binomial model with the command, "proc genmod" and "log link" to calculate the prevalence ratios by analyzing the effects of covariates concerning the association between NSC and insufficient sleep [60]. The analysis was conducted on each imputed data set, and we then pooled the results of 10 data sets for each gender, adjusting the standard errors appropriately. In addition we performed the 
subgroup analysis for the working age group (20-69) by considering the actual retirement age [61]. Statistical significance was set at a two-sided $P$-value $<0.05$. We used SAS ver. 9.4 software (SAS Institute, Cary, NC, USA) for all of the statistical analyses.

\section{Results}

The internal consistency reliability (Cronbach's $\alpha$ ) for the NSC questions was acceptably high at 0.86 . There was no significant correlation among the independent variables. Overall, 43.6\% (3370/7721) of the respondents experienced the insufficient sleep, with the mean duration of sleeping hours $6.8(\mathrm{SD}=1.34 \mathrm{~h})$. The mean sleep duration was not significantly different between the men $(6.8 \mathrm{~h})$ and the women $(6.7 \mathrm{~h})$. Although social activity or cooperation in relation to insufficient sleep had significant interaction test for gender $(P=0.009)$, none of NSC groups and other dimensions were significant for gender interaction test. However we performed all the analyses stratified by gender because of the considerable biological and psychosocial roles of gender in both NSC and sleep.

Table 1 summarizes the demographic characteristics of respondents by genders. More than half of the respondents were female $(n=4096 ; 53.1 \%), 45.3 \%$ of the women experienced the insufficient sleep, whereas $41.7 \%$ of the men did. More than $65.0 \%$ of both the men and the women were classified as having low education, and $43.6 \%$ of the men and $31.0 \%$ of the women were blue-collar workers. Approximately $50 \%$ of the men earned $\geq 4$ million yen/year, and the annual household income was higher in the men than the women. A total of $33.6 \%$ of the men were smokers and $21.4 \%$ were daily drinkers, whereas among the women, only $7.6 \%$ were smokers and $3.5 \%$ were daily drinkers. More than $40 \%$ of the respondents of both genders were physically inactive, and overweight or obesity was found in $24.5 \%$ of the men and $13.3 \%$ of the women. More than half of the respondents of both genders had one of the NCDs. The gender-stratified univariate analysis showed that all of the variables were significantly associated with insufficient sleep.

The characteristics of the participants across the NSC groups are shown in Table 2. The NSC scores among the NSC groups were not much different between the men and the women. The proportion of insufficient sleep of the highest NSC group in the women (42.4\%) was higher than that of the men (33.7\%). In both genders, older participants had higher NSC than younger participants. On the other hand other characteristics of the participants such as educational attainment, occupation, annual household income, smoking status, alcohol drinking, physical activity, BMI, and NCD were not much different among the NSC groups in both genders.
There were no interactions between NSC groups and socioeconomic factors in both genders, namely age $(P=0.96$ in men and $P=0.40$ in women), educational attainment ( $P=0.34$ in men and $P=0.67$ in women), occupation $(P=$ 0.07 in men and $P=0.45$ in women), annual household income ( $P=0.21$ in men and $P=0.88$ in women).

Table 3 describes the results of the multiple regression with log-binomial models using the multiple imputation method. Across all models, a significant association was found between NSC and insufficient sleep after controlling for all potential confounders in the men. Among the men, the lowest NSC group had 22\% higher prevalence of insufficient sleep (PR 1.22; 95\% CIs 1.08-1.38) compared to the highest NSC group. Similarly, the low NSC group and the high NSC group had 20 and 19\% higher prevalence of insufficient sleep (PR 1.20; 95\% CIs 1.06-1.36 and PR 1.19; 95\% CIs 1.06-1.34, respectively) compared to the highest NSC group. In contrast, for the women, there was no significant association between NSC and insufficient sleep after controlling for all potential confounders. Moreover similar pattern of associations were found in the men in the relationship between each dimension of NSC except the feeling of fellowship and insufficient sleep (Table 4). The subgroup analysis of the working age group also showed the significant association between NSC and insufficient sleep in both genders (see Additional file 1).

\section{Discussion}

Our findings demonstrated a significant relationship between NSC and sleep duration in men but not in women. In particular, NSC was negatively associated with insufficient sleep in the men even after controlling for all potential confounders. Each dimension of NSC except the feeling of fellowship, was also negatively related to insufficient sleep only in men. Furthermore, even in the working age group, the low NSC groups experienced the insufficient sleep more than the highest NSC group for both genders.

A few studies investigated the association between NSC and sleep duration by genders. The research by Toyosato and Takakura showed that through the sleep duration of women, the perceived trust of NSC was associated with self-rated health, and the authors proposed that NSC should be promoted for the improvement of sleep duration in Japanese women [8]. In contrary, our study found that low NSC was related to insufficient sleep in men but not in women. Although the reason for a discrepancy was unclear, results from both studies suggested there were gender differences in the relationship between NSC and sleep duration. Thus further prospective study is needed on the association between NSC and health behavior considering the gender pattern. 
Table 1 Demographic characteristic of the respondents

\begin{tabular}{|c|c|c|}
\hline & $\begin{array}{l}\text { Men } \\
(n=3625,46.9 \%)\end{array}$ & $\begin{array}{l}\text { Women } \\
(n=4096,53.1 \%)\end{array}$ \\
\hline Characteristics & No. & No. \\
\hline
\end{tabular}

Neighborhood social capital

$\begin{array}{lllll}\text { Lowest } & 812 & (22.4) & 865 & (21.1) \\ \text { Low } & 852 & (23.5) & 901 & (22.0) \\ \text { High } & 1021 & (28.2) & 1189 & (29.0) \\ \text { Highest } & 736 & (20.3) & 868 & (21.2) \\ \text { Missing } & 204 & (5.6) & 273 & (6.7)\end{array}$

Age (years)

$\begin{array}{llll}20-39 & 935 & (25.8) & 1036 \\ 40-59 & 1208 & (33.3) & 1346 \\ 60-79 & 1198 & (33.1) & 128 \\ \geq 80 & 284 & (7.8) & 428\end{array}$

Educational attainment

$\begin{array}{lllll}\text { Low } & 2496 & (68.9) & 2774 & (67.7) \\ \text { Medium } & 329 & (9.1) & 904 & (22.1) \\ \text { High } & 755 & (20.8) & 335 & (8.2) \\ \text { Missing } & 45 & (1.2) & 83 & \text { (2.0) }\end{array}$

Occupation

$\begin{array}{lllll}\text { Blue collar } & 1581 & (43.6) & 1270 & \text { (31.0) } \\ \text { White collar } & 1111 & (30.7) & 1026 & (25.1) \\ \text { Others } & 852 & (23.5) & 1711 & \text { (41.8) } \\ \text { Missing } & 81 & (2.2) & 89 & \text { (2.2) }\end{array}$

Annual household income (Million Yen)

$\begin{array}{lllll}<2 & 105 & (2.9) & 174 & (4.3) \\ 2-3.99 & 502 & (13.9) & 526 & (12.8) \\ 4-5.99 & 602 & (16.6) & 572 & (14.0) \\ 6-7.99 & 485 & (13.4) & 483 & (11.8) \\ \geq 8 & 708 & (19.5) & 657 & (16.0) \\ \text { Missing } & 1223 & (33.7) & 1684 & (41.1)\end{array}$

Smoking status

$\begin{array}{lllll}\text { Non-smoker } & 1909 & (52.7) & 3629 & \text { (88.6) } \\ \text { Ex-smoker } & 464 & (12.8) & 117 & (2.9) \\ \text { Smoker } & 1217 & (33.6) & 313 & (7.6) \\ \text { Missing } & 35 & (1.0) & 37 & (0.9) \\ \text { Alcohol Drinking } & & & & \\ \text { Non-drinker } & 1453 & (40.1) & 2971 & (72.5) \\ \text { Occasional drinker } & 1366 & (37.7) & 946 & (23.1) \\ \text { Daily drinker } & 775 & (21.4) & 142 & (3.5) \\ \text { Missing } & 31 & (0.9) & 37 & (0.9)\end{array}$

Physical activity

$\begin{array}{lllll}\text { Active } & 1517 & (41.9) & 1490 & (36.4) \\ \text { Inactive } & 1593 & (43.9) & 1993 & (48.7) \\ \text { Missing } & 515 & (14.2) & 613 & \text { (15.0) }\end{array}$

Table 1 Demographic characteristic of the respondents (Continued)

\begin{tabular}{|c|c|c|c|c|}
\hline \multirow[b]{2}{*}{ Characteristics } & \multicolumn{2}{|c|}{$\begin{array}{l}\text { Men } \\
(n=3625,46.9 \%)\end{array}$} & \multicolumn{2}{|c|}{$\begin{array}{l}\text { Women } \\
(n=4096,53.1 \%)\end{array}$} \\
\hline & No. & (\%) & No. & (\%) \\
\hline \multicolumn{5}{|l|}{ BMI $\left(\mathrm{kg} / \mathrm{m}^{2}\right)$} \\
\hline Underweight & 198 & $(5.5)$ & 525 & $(12.8)$ \\
\hline Normal & 2432 & $(67.1)$ & 2818 & $(68.8)$ \\
\hline Overweight & 781 & (21.5) & 469 & $(11.5)$ \\
\hline Obese & 110 & (3.0) & 72 & $(1.8)$ \\
\hline Missing & 104 & $(2.9)$ & 212 & $(5.2)$ \\
\hline \multicolumn{5}{|c|}{ Non-communicable disease } \\
\hline Present & 1859 & (51.3) & 2175 & $(53.1)$ \\
\hline Absent & 1717 & $(47.4)$ & 1858 & $(45.4)$ \\
\hline Missing & 49 & (1.4) & 63 & $(1.5)$ \\
\hline \multicolumn{5}{|l|}{ Insufficient sleep } \\
\hline Yes & 1513 & $(41.7)$ & 1857 & $(45.3)$ \\
\hline No & 1941 & $(53.5)$ & 2014 & $(49.2)$ \\
\hline Missing & 171 & $(4.7)$ & 225 & $(5.5)$ \\
\hline
\end{tabular}

Another study in Finland demonstrated a positive association between NSC and adequate sleep of 7-8 h per night [7]. Our present findings are supported by that study, which specifically indicated that people with high levels of social participation and networks were likely to have healthier behaviors than those with low levels although the authors did not take account for the gender differences in the analysis. In contrast, Mohnen et al. [3] reported that they observed no association between NSC and sleeping habits. As the authors did not access a gender disparity in the analysis, it may lead to the different results from ours. Another explanation for the inconsistent results between the studies may be due to varying approaches of social capital [62]; while the authors assessed NSC using a collective approach, we used an individual approach. Furthermore, all of the studies mentioned above treated sleep duration as a mediator between NSC and health outcomes. However, we investigated the direct association considering other potential confounders, which were not fully examined in the previous studies. Moreover, we analyzed the association by different dimensions of NSC. These characteristics of our studies guarantee the robustness of our results.

A handful studies have described a direct relationship between NSC and sleep disturbances, which supports our findings. Takahashi et al. [9] reported that Japanese workers who had higher neighborhood or workplace social capital had a better quality and quantity of sleep. Their finding was similar to our results from subgroup analysis although the authors did not consider gender effects in the study. One of the reasons for the 
Table 2 Characteristic distribution of respondents among neighborhood social capital groups

\begin{tabular}{|c|c|c|c|c|c|c|c|c|c|c|c|c|c|c|c|c|}
\hline \multirow[b]{5}{*}{ Characteristics } & \multicolumn{16}{|c|}{ Neighborhood social capital $(n=7244)$} \\
\hline & \multicolumn{8}{|c|}{ Men $(n=3421)$} & \multicolumn{8}{|c|}{ Women $(n=3823)$} \\
\hline & \multirow{2}{*}{\multicolumn{2}{|c|}{$\frac{\text { Lowest }}{(n=812)}$}} & \multirow{2}{*}{\multicolumn{2}{|c|}{$\frac{\text { Low }}{(n=852)}$}} & \multirow{2}{*}{\multicolumn{2}{|c|}{$\begin{array}{l}\text { High } \\
(n=1021)\end{array}$}} & \multirow{2}{*}{\multicolumn{2}{|c|}{$\begin{array}{l}\text { Highest } \\
(n=736)\end{array}$}} & \multirow{2}{*}{\multicolumn{2}{|c|}{$\frac{\text { Lowest }}{(n=865)}$}} & \multirow{2}{*}{\multicolumn{2}{|c|}{$\frac{\text { Low }}{(n=901)}$}} & \multirow{2}{*}{\multicolumn{2}{|c|}{$\begin{array}{l}\text { High } \\
(n=1189)\end{array}$}} & \multirow{2}{*}{\multicolumn{2}{|c|}{$\begin{array}{l}\text { Highest } \\
(n=868)\end{array}$}} \\
\hline & & & & & & & & & & & & & & & & \\
\hline & No. & $\%$ or SD & No. & $\%$ or SD & No. & $\%$ or SD & No. & $\%$ or SD & No. & $\%$ or SD & No. & $\%$ or SD & No. & $\%$ or SD & No. & $\%$ or SD \\
\hline \multicolumn{17}{|c|}{ Neighborhood social capital scores } \\
\hline Mean & 10.1 & (2.6) & 15.1 & $(0.6)$ & 18.6 & $(1.1)$ & 23.0 & (1.6) & 10.1 & $(2.6)$ & 15.1 & $(0.7)$ & 18.6 & $(1.1)$ & 22.9 & $(1.6)$ \\
\hline \multicolumn{17}{|l|}{ Age (years) } \\
\hline 20-39 & 310 & $(38.2)$ & 324 & $(38.0)$ & 180 & $(17.6)$ & 93 & $(12.6)$ & 339 & $(39.2)$ & 295 & $(32.7)$ & 255 & $(21.5)$ & 124 & $(14.3)$ \\
\hline $40-59$ & 267 & $(32.9)$ & 295 & (34.6) & 395 & $(38.7)$ & 212 & $(28.8)$ & 303 & $(35.0)$ & 318 & (35.3) & 443 & (37.3) & 240 & $(27.7)$ \\
\hline $60-79$ & 193 & (23.8) & 197 & $(23.1)$ & 376 & $(36.8)$ & 350 & $(47.6)$ & 155 & $(17.9)$ & 211 & $(23.4)$ & 395 & $(33.2)$ & 397 & $(45.7)$ \\
\hline$\geq 80$ & 42 & $(5.2)$ & 36 & $(4.2)$ & 70 & (6.9) & 81 & $(11.0)$ & 68 & (7.9) & 77 & (8.6) & 96 & (8.1) & 107 & $(12.3)$ \\
\hline \multicolumn{17}{|l|}{ Educational attainment } \\
\hline Low & 532 & $(66.1)$ & 555 & $(65.8)$ & 686 & $(67.7)$ & 566 & $(77.5)$ & 505 & $(59.9)$ & 603 & $(67.9)$ & 819 & $(69.5)$ & 637 & $(74.5)$ \\
\hline Medium & 82 & $(10.2)$ & 96 & $(11.4)$ & 88 & (8.7) & 55 & $(7.5)$ & 227 & $(26.9)$ & 212 & $(23.9)$ & 261 & $(22.2)$ & 174 & (20.4) \\
\hline High & 191 & $(23.7)$ & 192 & $(22.8)$ & 240 & $(23.7)$ & 109 & $(14.9)$ & 111 & (13.2) & 73 & (8.2) & 98 & (8.3) & 44 & $(5.2)$ \\
\hline \multicolumn{17}{|l|}{ Occupation } \\
\hline Blue collar & 369 & (45.8) & 390 & $(46.0)$ & 432 & $(42.6)$ & 332 & $(45.5)$ & 285 & (33.4) & 291 & $(32.6)$ & 363 & (30.8) & 277 & $(32.1)$ \\
\hline White collar & 266 & (33.0) & 275 & $(32.5)$ & 345 & $(34.0)$ & 204 & (28.0) & 267 & (31.3) & 256 & $(28.7)$ & 324 & $(27.5)$ & 156 & (18.1) \\
\hline Others & 170 & $(21.1)$ & 182 & $(21.5)$ & 237 & $(23.4)$ & 193 & $(26.5)$ & 301 & (35.3) & 345 & $(38.7)$ & 493 & $(41.8)$ & 429 & (49.8) \\
\hline \multicolumn{17}{|c|}{ Annual household income (Million yen) } \\
\hline$<2$ & 25 & (4.8) & 22 & $(4.2)$ & 29 & (3.9) & 22 & $(4.1)$ & 29 & $(5.7)$ & 46 & (8.4) & 54 & (7.1) & 31 & (6) \\
\hline 2-3.99 & 126 & $(24.1)$ & 104 & $(19.6)$ & 139 & $(18.6)$ & 120 & $(22.4)$ & 115 & $(22.5)$ & 116 & $(21.3)$ & 157 & $(20.5)$ & 115 & $(22.2)$ \\
\hline $4-5.99$ & 137 & $(26.2)$ & 129 & $(24.3)$ & 176 & $(23.6)$ & 141 & $(26.3)$ & 120 & $(23.4)$ & 117 & $(21.4)$ & 191 & $(24.9)$ & 127 & $(24.6)$ \\
\hline $6-7.99$ & 94 & (18.1) & 117 & $(22.1)$ & 160 & $(21.5)$ & 103 & $(19.2)$ & 97 & (19.0) & 111 & $(20.3)$ & 158 & (20.6) & 111 & $(21.5)$ \\
\hline$\geq 8$ & 141 & $(27.0)$ & 158 & $(29.8)$ & 242 & $(32.4)$ & 150 & $(28.0)$ & 151 & $(29.5)$ & 156 & $(28.6)$ & 206 & $(26.9)$ & 133 & $(25.7)$ \\
\hline \multicolumn{17}{|l|}{ Smoking status } \\
\hline Non-smoker & 398 & $(49.4)$ & 421 & $(49.7)$ & 531 & $(52.3)$ & 423 & $(57.8)$ & 720 & $(84.2)$ & 776 & $(86.6)$ & 1082 & $(91.3)$ & 802 & $(93.4)$ \\
\hline Ex-smoker & 112 & (13.9) & 97 & $(11.5)$ & 150 & $(14.8)$ & 91 & $(12.4)$ & 31 & (3.6) & 35 & (3.9) & 27 & (2.3) & 21 & (2.4) \\
\hline Smoker & 295 & (36.7) & 329 & $(38.8)$ & 335 & $(33.0)$ & 218 & $(29.8)$ & 104 & $(12.2)$ & 85 & (9.5) & 76 & (6.4) & 36 & $(4.2)$ \\
\hline Alcohol Drinking & & & & & & & & & & & & & & & & \\
\hline Non-drinker & 336 & $(41.6)$ & 358 & $(42.2)$ & 356 & $(35.0)$ & 295 & $(40.4)$ & 568 & $(66.2)$ & 634 & $(70.5)$ & 856 & $(72.5)$ & 675 & (78.7) \\
\hline Occasional drinker & 313 & (38.8) & 328 & $(38.7)$ & 419 & $(41.2)$ & 250 & $(34.3)$ & 251 & $(29.3)$ & 238 & $(26.5)$ & 275 & $(23.3)$ & 159 & $(18.5)$ \\
\hline Daily drinker & 158 & (19.6) & 162 & $(19.1)$ & 241 & $(23.7)$ & 185 & $(25.3)$ & 39 & (4.6) & 27 & (3.0) & 50 & $(4.2)$ & 24 & $(2.8)$ \\
\hline Physical activity & & & & & & & & & & & & & & & & \\
\hline Active & 310 & $(44.2)$ & 337 & $(45.7)$ & 479 & $(53.2)$ & 336 & $(53.0)$ & 279 & $(37.7)$ & 318 & $(40.1)$ & 460 & $(45.0)$ & 379 & $(50.7)$ \\
\hline Inactive & 392 & $(55.8)$ & 401 & $(54.3)$ & 421 & $(46.8)$ & 298 & $(47.0)$ & 461 & $(62.3)$ & 475 & $(59.9$ & 562 & $(55.0)$ & 369 & $(49.3)$ \\
\hline BMI $\left(\mathrm{Kg} / \mathrm{m}^{2}\right)$ & & & & & & & & & & & & & & & & \\
\hline Underweight & 55 & (7.0) & 50 & $(6.0)$ & 45 & $(4.5)$ & 29 & $(4.0)$ & 135 & $(16.5)$ & 110 & $(12.9)$ & 142 & $(12.5)$ & 106 & $(12.6)$ \\
\hline Normal & 512 & (64.8) & 584 & $(69.9)$ & 700 & $(69.8)$ & 512 & $(71.4)$ & 576 & $(70.4)$ & 627 & $(73.4)$ & 837 & $(73.7)$ & 612 & $(72.9)$ \\
\hline Overweight & 188 & (23.8) & 178 & $(21.3)$ & 226 & $(22.5)$ & 158 & $(22.0)$ & 88 & (10.8) & 100 & $(11.7)$ & 131 & $(11.5)$ & 113 & $(13.5)$ \\
\hline Obese & 35 & $(4.4)$ & 24 & (2.9) & 32 & $(3.2)$ & 18 & $(2.5)$ & 19 & $(2.3)$ & 17 & (2.0) & 25 & $(2.2)$ & 9 & $(1.1)$ \\
\hline Non-communicable d & lisease: & & & & & & & & & & & & & & & \\
\hline Present & 374 & $(46.8)$ & 392 & $(46.3)$ & 548 & $(54.3)$ & 427 & $(58.6)$ & 420 & $(49.5)$ & 432 & $(48.6)$ & 626 & $(53.0)$ & 524 & $(61.0)$ \\
\hline Absent & 426 & (53.3) & 454 & (53.7) & 461 & $(45.7)$ & 302 & (41.4) & 428 & (50.5) & 457 & (51.4) & 556 & $(47.0)$ & 335 & (39.0) \\
\hline
\end{tabular}


Table 2 Characteristic distribution of respondents among neighborhood social capital groups (Continued)

\begin{tabular}{|c|c|c|c|c|c|c|c|c|c|c|c|c|c|c|c|c|}
\hline \multirow[b]{5}{*}{ Characteristics } & \multicolumn{16}{|c|}{ Neighborhood social capital $(n=7244)$} \\
\hline & \multicolumn{8}{|c|}{ Men $(n=3421)$} & \multicolumn{8}{|c|}{ Women $(n=3823)$} \\
\hline & \multirow{2}{*}{\multicolumn{2}{|c|}{$\frac{\text { Lowest }}{(n=812)}$}} & \multirow{2}{*}{\multicolumn{2}{|c|}{$\frac{\text { Low }}{(n=852)}$}} & \multirow{2}{*}{\multicolumn{2}{|c|}{$\frac{\text { High }}{(n=1021)}$}} & \multirow{2}{*}{\multicolumn{2}{|c|}{$\frac{\text { Highest }}{(n=736)}$}} & \multirow{2}{*}{\multicolumn{2}{|c|}{$\frac{\text { Lowest }}{(n=865)}$}} & \multirow{2}{*}{\multicolumn{2}{|c|}{$\frac{\text { Low }}{(n=901)}$}} & \multirow{2}{*}{\multicolumn{2}{|c|}{$\frac{\text { High }}{(n=1189)}$}} & \multirow{2}{*}{\multicolumn{2}{|c|}{$\frac{\text { Highest }}{(n=868)}$}} \\
\hline & & & & & & & & & & & & & & & & \\
\hline & No. & $\%$ or SD & No. & $\%$ or SD & No. & $\%$ or SD & No. & $\%$ or SD & No. & $\%$ or SD & No. & $\%$ or SD & No. & $\%$ or SD & No. & $\%$ or SD \\
\hline \multicolumn{17}{|l|}{ Sleeping time } \\
\hline Mean & 6.7 & $(1.4)$ & 6.7 & $(1.3)$ & 6.8 & $(1.3)$ & 7.1 & $(1.3)$ & 6.6 & (1.4) & 6.7 & $(1.4)$ & 6.7 & $(1.3)$ & 6.9 & $(1.2)$ \\
\hline \multicolumn{17}{|c|}{ Insufficient sleep } \\
\hline Yes & 385 & $(49.0)$ & 392 & $(47.9)$ & 446 & $(44.9)$ & 238 & $(33.7)$ & 429 & $(51.6)$ & 435 & $(50.5)$ & 568 & $(48.8)$ & 352 & $(42.4)$ \\
\hline No & 400 & (51) & 427 & (52.1) & 548 & $(55.1)$ & 468 & $(66.3)$ & 403 & $(48.4)$ & 426 & $(49.5)$ & 595 & $(51.2)$ & 479 & (57.6) \\
\hline
\end{tabular}

association between higher social capital and a better sleep among workers may be due to the barrier effect, where NSC acts as the shock absorber to the stress and strain of the workplace [63,64]. Another possibility is that NSC relieves psychosocial or environmental stresses which disturb the sleep [65] via the mental wellbeing obtained from mutual trust, reciprocity, wider social networks and social supports [66, 67]. Moreover Bassett and Moore [10] argued that the lower neighborhood trust in a Canadian community increased the likelihood of restless sleep in women and that lower network social capital increased the likelihood of restless sleep in men. On the other hand, our results demonstrated that all dimensions of NSC were associated with insufficient sleep in men, but not in women. We speculate that social roles and responsibilities may shape sleep disturbances differently in men and women.

David-Barrett $\mathrm{T}$ et al. reported that men have larger social networks and higher thin trust each other compared to women [68]. In Japan, men are likely to spend longer time on active free-time activities, work and work-related activities than women [21]. Because of these activities outside, Japanese men may build social network from accumulating social norms or shared value through the expended loose social networks, which may relieve the distresses of sleep disturbance [12]. On the other hand, women in Japan accept gendered responsibility and have a desire to fulfill their social role as mother, spouse and caretaker for children and other family members [69]. In addition women generally tend to build emotional based, time-consuming kinship relationship among family members and close friends which creates fewer friendships or social networks with thick trust in women [68]. According to a report by statistics bureau in Japan [21], women tend to spend more time on communication with family members and thus they are likely to create thick trust and fewer social networks than men. Moreover Japanese women spend more time on child caring, care-giving and unpaid housework than men [21]. These responsibilities in women may relate to higher levels of depression, anxiety and affection, causing insufficient sleep. Another possibility is that hormonal effects during pregnancy, lactation, pre- and postmenstrual states, and/or pre- and post-menopause status in women induce sleep disturbances [38].

A number of explanations may account for the association between NSC and sleep duration. First, stressful conditions in a neighborhood contribute to alterations

Table 3 Prevalence ratios of neighborhood social capital for insufficient sleep of respondents

\begin{tabular}{|c|c|c|c|c|c|c|c|c|c|}
\hline & & \multicolumn{2}{|c|}{ Crude Model } & \multicolumn{2}{|c|}{ Model $1^{a}$} & \multicolumn{2}{|c|}{ Model $2^{b}$} & \multicolumn{2}{|c|}{ Model $3^{c}$} \\
\hline & & PR & $95 \% \mathrm{Cl}$ & $\mathrm{PR}$ & $95 \% \mathrm{Cl}$ & PR & $95 \% \mathrm{Cl}$ & $\mathrm{PR}$ & $95 \% \mathrm{Cl}$ \\
\hline \multirow[t]{4}{*}{ Men } & Lowest & 1.47 & $(1.30-1.66)$ & 1.22 & $(1.08-1.37)$ & 1.24 & $(1.10-1.40)$ & 1.22 & $(1.08-1.38)$ \\
\hline & Low & 1.44 & $(1.27-1.63)$ & 1.18 & $(1.05-1.34)$ & 1.21 & $(1.07-1.36)$ & 1.20 & $(1.06-1.36)$ \\
\hline & High & 1.33 & $(1.17-1.51)$ & 1.21 & $(1.07-1.36)$ & 1.20 & $(1.07-1.35)$ & 1.19 & $(1.06-1.34)$ \\
\hline & Highest & \multicolumn{2}{|c|}{ Reference } & \multicolumn{2}{|c|}{ Reference } & \multicolumn{2}{|c|}{ Reference } & \multicolumn{2}{|c|}{ Reference } \\
\hline \multirow[t]{4}{*}{ Women } & Lowest & 1.22 & $(1.10-1.36)$ & 1.10 & $(1.00-1.22)$ & 1.11 & $(1.00-1.22)$ & 1.11 & $(1.00-1.22)$ \\
\hline & Low & 1.20 & $(1.08-1.34)$ & 1.11 & $(1.00-1.22)$ & 1.10 & $(1.00-1.22)$ & 1.10 & $(1.00-1.22)$ \\
\hline & High & 1.17 & $(1.06-1.29)$ & 1.09 & $(0.99-1.19)$ & 1.08 & $(0.99-1.19)$ & 1.08 & $(0.98-1.19)$ \\
\hline & Highest & \multicolumn{2}{|c|}{ Reference } & \multicolumn{2}{|c|}{ Reference } & \multicolumn{2}{|c|}{ Reference } & \multicolumn{2}{|c|}{ Reference } \\
\hline
\end{tabular}

\footnotetext{
a: Adjusted for age

${ }^{\mathrm{b}}$ : Adjusted for age, education, occupation, and annual household income

c: Adjusted for age, education, occupation, annual household income, smoking, alcohol drinking, physical activity, BMI and presence of NCD
} 
Table 4 Prevalence ratios of each neighborhood social capital dimension for insufficient sleep of respondents

\begin{tabular}{|c|c|c|c|c|c|c|c|c|c|}
\hline \multicolumn{4}{|c|}{ Crude Model } & \multicolumn{2}{|c|}{ Model $1^{\text {a }}$} & \multicolumn{2}{|c|}{ Model $2^{b}$} & \multicolumn{2}{|c|}{ Model $3^{c}$} \\
\hline & $\mathrm{PR}$ & \multicolumn{2}{|c|}{$95 \% \mathrm{Cl}$} & $\mathrm{PR}$ & $95 \% \mathrm{Cl}$ & $\mathrm{PR}$ & $95 \% \mathrm{Cl}$ & $\mathrm{PR}$ & $95 \% \mathrm{Cl}$ \\
\hline \multicolumn{10}{|c|}{ Feeling of fellowship } \\
\hline \multirow[t]{4}{*}{ Men } & Lowest & 1.36 & $(1.20-1.53)$ & 1.17 & $(1.04-1.32)$ & 1.21 & $(1.08-1.36)$ & 1.19 & $(1.06-1.34)$ \\
\hline & Low & 1.43 & $(1.29-1.58)$ & 1.19 & $(1.07-1.31)$ & 1.22 & $(1.10-1.35)$ & 1.21 & $(1.09-1.34)$ \\
\hline & High & 1.22 & $(1.09-1.36)$ & 1.11 & $(1.00-1.23)$ & 1.12 & $(1.01-1.24)$ & 1.12 & $(1.01-1.24)$ \\
\hline & Highest & \multicolumn{2}{|c|}{ Reference } & \multicolumn{2}{|c|}{ Reference } & \multicolumn{2}{|c|}{ Reference } & \multicolumn{2}{|c|}{ Reference } \\
\hline \multirow[t]{4}{*}{ Women } & Lowest & 1.21 & $(1.09-1.35)$ & 1.14 & $(1.03-1.26)$ & 1.15 & $(1.04-1.27)$ & 1.15 & $(1.04-1.27)$ \\
\hline & Low & 1.24 & $(1.14-1.36)$ & 1.11 & $(1.02-1.21)$ & 1.13 & $(1.03-1.23)$ & 1.12 & $(1.03-1.22)$ \\
\hline & High & 1.17 & $(1.07-1.28)$ & 1.08 & $(0.99-1.18)$ & 1.08 & $(0.99-1.18)$ & 1.08 & $(0.99-1.18)$ \\
\hline & Highest & \multicolumn{2}{|c|}{ Reference } & \multicolumn{2}{|c|}{ Reference } & \multicolumn{2}{|c|}{ Reference } & \multicolumn{2}{|c|}{ Reference } \\
\hline \multicolumn{10}{|c|}{ Emotional Social Support } \\
\hline \multirow[t]{4}{*}{ Men } & Lowest & 1.50 & $(1.31-1.72)$ & 1.29 & $(1.13-1.47)$ & 1.29 & $(1.13-1.47)$ & 1.28 & $(1.12-1.46)$ \\
\hline & Low & 1.40 & $(1.23-1.61)$ & 1.26 & $(1.11-1.44)$ & 1.26 & $(1.11-1.43)$ & 1.26 & $(1.11-1.43)$ \\
\hline & High & 1.26 & $(1.09-1.47)$ & 1.22 & $(1.06-1.41)$ & 1.21 & $(1.05-1.40)$ & 1.21 & $(1.05-1.39)$ \\
\hline & Highest & \multicolumn{2}{|c|}{ Reference } & \multicolumn{2}{|c|}{ Reference } & \multicolumn{2}{|c|}{ Reference } & \multicolumn{2}{|c|}{ Reference } \\
\hline Women & Lowest & 1.07 & $(0.97-1.18)$ & 1.01 & $(0.92-1.11)$ & 1.01 & $(0.92-1.10)$ & 1.01 & $(0.92-1.10)$ \\
\hline & Low & 1.09 & $(0.99-1.20)$ & 1.05 & $(0.96-1.15)$ & 1.06 & $(0.97-1.15)$ & 1.06 & $(0.97-1.15)$ \\
\hline & High & 1.05 & $(0.95-1.16)$ & 1.01 & $(0.92-1.11)$ & 1.00 & $(0.92-1.10)$ & 1.00 & $(0.92-1.10)$ \\
\hline & Highest & Refer & & Refer & & Refer & & Refer & \\
\hline Reciproci & & & & & & & & & \\
\hline Men & Lowest & 1.08 & $(0.94-1.25)$ & 1.00 & $(0.88-1.14)$ & 1.04 & $(0.91-1.19)$ & 1.02 & $(0.89-1.16)$ \\
\hline & Low & 1.25 & $(1.12-1.39)$ & 1.10 & $(1.00-1.22)$ & 1.15 & $(1.04-1.27)$ & 1.14 & $(1.03-1.26)$ \\
\hline & High & 1.15 & $(1.03-1.29)$ & 1.08 & $(0.96-1.20)$ & 1.08 & $(0.97-1.20)$ & 1.07 & $(0.96-1.19)$ \\
\hline & Highest & Refer & & Refer & & Refer & & Refer & \\
\hline Women & Lowest & 1.21 & $(1.07-1.36)$ & 1.11 & $(0.99-1.25)$ & 1.12 & $(1.00-1.25)$ & 1.11 & $(0.99-1.24)$ \\
\hline & Low & 1.20 & $(1.09-1.32)$ & 1.08 & $(0.99-1.19)$ & 1.09 & $(0.99-1.19)$ & 1.08 & $(0.99-1.18)$ \\
\hline & High & 1.17 & $(1.06-1.30)$ & 1.11 & $(1.01-1.22)$ & 1.10 & $(1.00-1.21)$ & 1.09 & $(0.99-1.20)$ \\
\hline & Highest & Refer & & Refe & & Refer & & Refer & \\
\hline Perceivec & aborhood & & & & & & & & \\
\hline Men & Lowest & 1.47 & $(1.25-1.74)$ & 1.17 & $(1.00-1.37)$ & 1.19 & $(1.02-1.39)$ & 1.19 & $(1.02-1.38)$ \\
\hline & Low & 1.47 & $(1.26-1.71)$ & 1.18 & $(1.02-1.36)$ & 1.19 & $(1.03-1.37)$ & 1.18 & $(1.03-1.36)$ \\
\hline & High & 1.34 & $(1.14-1.58)$ & 1.17 & $(1.00-1.36)$ & 1.18 & $(1.01-1.37)$ & 1.17 & $(1.01-1.36)$ \\
\hline & Highest & Refer & & Refer & & Refer & & Refer & \\
\hline Women & Lowest & 1.35 & $(1.17-1.55)$ & 1.13 & $(0.99-1.30)$ & 1.14 & $(1.00-1.31)$ & 1.13 & $(0.99-1.30)$ \\
\hline & Low & 1.39 & $(1.22-1.57)$ & 1.15 & $(1.02-1.29)$ & 1.15 & $(1.02-1.29)$ & 1.14 & $(1.01-1.28)$ \\
\hline & High & 1.24 & $(1.09-1.42)$ & 1.10 & $(0.96-1.25)$ & 1.08 & $(0.96-1.23)$ & 1.08 & $(0.95-1.23)$ \\
\hline & Highest & Refer & & Refer & & Refer & & Refer & \\
\hline Social ac & r co-opera & & & & & & & & \\
\hline Men & Lowest & 1.44 & $(1.26-1.65)$ & 1.22 & $(1.07-1.39)$ & 1.24 & $(1.08-1.41)$ & 1.20 & $(1.06-1.37)$ \\
\hline & Low & 1.38 & $(1.22-1.57)$ & 1.21 & $(1.06-1.37)$ & 1.23 & $(1.08-1.39)$ & 1.21 & $(1.07-1.37)$ \\
\hline & High & 1.31 & $(1.14-1.51)$ & 1.22 & $(1.07-1.39)$ & 1.20 & $(1.05-1.37)$ & 1.18 & $(1.03-1.34)$ \\
\hline & Highest & Refer & & Refer & & Refer & & Refer & \\
\hline Women & Lowest & 1.18 & $(1.05-1.32)$ & 1.05 & $(0.94-1.17)$ & 1.04 & $(0.93-1.16)$ & 1.03 & $(0.93-1.15)$ \\
\hline & Low & 1.15 & $(1.03-1.28)$ & 1.03 & $(0.93-1.14)$ & 1.01 & $(0.92-1.12)$ & 1.01 & $(0.91-1.12)$ \\
\hline
\end{tabular}


Table 4 Prevalence ratios of each neighborhood social capital dimension for insufficient sleep of respondents (Continued)

\begin{tabular}{|c|c|c|c|c|c|c|c|c|}
\hline \multicolumn{3}{|c|}{ Crude Model } & \multicolumn{2}{|c|}{ Model $1^{a}$} & \multicolumn{2}{|c|}{ Model $2^{b}$} & \multicolumn{2}{|c|}{ Model $3^{c}$} \\
\hline$\overline{P R}$ & $95 \%$ & & $\overline{P R}$ & $95 \% \mathrm{Cl}$ & $\mathrm{PR}$ & $95 \% \mathrm{Cl}$ & $\overline{P R}$ & $95 \% \mathrm{Cl}$ \\
\hline High & 1.14 & $(1.01-1.28)$ & 1.03 & $(0.92-1.15)$ & 1.02 & $(0.91-1.14)$ & 1.01 & $(0.90-1.13)$ \\
\hline Highest & \multicolumn{2}{|c|}{ Reference } & \multicolumn{2}{|c|}{ Reference } & \multicolumn{2}{|c|}{ Reference } & \multicolumn{2}{|c|}{ Reference } \\
\hline
\end{tabular}

${ }^{\text {a Adjusted for age }}$

${ }^{\mathrm{b}}$ Adjusted for age, education, occupation, and annual household income

'Adjusted for age, education, occupation, annual household income, smoking, alcohol drinking, physical activity, BMI and presence of NCD

of the adaptive nature of sleep through psychosocialcognitive pathways, because sleep has been recognized as largely psychological influential behavior [70, 71]. Second, living in a trustable community makes one feel safe and secure, which can contribute to falling asleep. Braithwaite [72] explained that unsafe, distrustful and highly stressed neighborhood conditions may relate to poor sleep. Third, a sense of membership in one's community endows people with self-esteem, which acts as a social experience to alter health behavior [73]. Fourth, loosely knit relationships among residents adversely affect individuals' psychological well-being, which is important for good sleep [74]. Finally, a neighborhood can give support for the distribution of information on healthy behaviors. A study in a Dutch community indicated that social support and information were potentially important for modifying health behaviors [75]. Although several mechanisms have been considered to underlie the association between NSC and sleep duration, the existence of a gender difference in that association was not clear until now.

Our study has several limitations. First, due to the study's cross-sectional design, we were not able to analyze the cause-effect relationship between NSC and insufficient sleep. Thus, insufficient sleep itself may adversely affect both physical and mental well-being, which in turn has a negative impact on NSC. Future studies should examine the causal relationship in the gender gap between social capital and sleep duration. Second, the validity of NSC was not accessed and thus the conclusions should be drawn with a caution although we had advantages of imparting different dimensions of NSC. The development of validated questionnaires for NSC will be required in future researches for generalizability. Third, we evaluated the respondents' subjective sleep duration as a main outcome variable using a self-reported questionnaire. Although we used self-reported sleep duration in our study, a previous study demonstrated that using self-reported results was as reliable as the objective assessments [76]. Thus a comprehensive approach including wrist actigraphy should be performed. In addition, evaluating sleep quality is important for sleep examinations, but we could not assess sleep quality as well as other complex disorders of sleep in this study. We also dichotomized the variable of sleep duration, and doing so could have under- or overestimated the results. Forth, our respond rate of $63.2 \%$ was not much high so that it might lead to selection bias. Finally, we used several factors to control confounding effects, but other unmeasured possible confounders such as stress might affect the association between social capital and insufficient sleep.

\section{Conclusions}

Our present findings demonstrated that having lower NSC was associated with insufficient sleep among Japanese adults, particularly among men. From a perspective of public health, social and environmental factors are modifiable and adaptable to healthier behaviors. Population-based studies of gender gap in NSC and sleep duration are worth conducting, toward the promotion of positive health-related behaviors. The context of NSC with gender differences should be considered when implementing interventions, strategies and policies to promote healthier behaviors regarding adequate amounts of sleep.

\section{Additional file}

Additional file 1: Prevalence ratios of neighborhood social capital in working age group for insufficient sleep of respondents. (DOCX $30 \mathrm{~kb}$ )

\section{Abbreviations \\ BMI: Body mass index; Cls: Confidence intervals; FCS: Fully conditional specification; hrs: hours; MI: Multiple imputation; NCDs: Non-communicable diseases; NSC: Neighborhood social capital; OECD: Organization for Economic Co-operation and Development; P: P-value; PRs: Prevalence ratios; TOL: Tolerance value; VIF: Variance inflation factor; WHO: World Health Organization}

\begin{abstract}
Acknowledgements
The authors cordially thank the participants of the study, and the staff and associates of the Tamaki Town Office and Kihoku Town Office. We also thank the many people who contributed to establishing this project. The complete lists of collaborators in the Study are as follows: Ippei Mori, Kazumune Ueshima, Tomomi Yamada, Akihide Shimada, Ichiro Kawachi, Suminori Akiba, Naohito Yamaguchi, Hidehiko Tamashiro, Kentaro Higashi, Tatsuro Miyake, Tetsunori Ozaki, Yoshiyuki Kusui, Kunihiko Takahashi, Yuka Matsumoto, Yuichi Nakayama, Yuki Goto, Kaoru Nakane, and Michiko Shimada.
\end{abstract}

Funding

This research was supported by the Fund to revitalize the community healthcare in Mie Prefecture. 


\section{Availability of data and materials}

The datasets generated and/or analyzed during the current study are not publicly available due to confidentiality of respondents but are available from the corresponding author on reasonable request.

\section{Authors' contributions}

TY and SS conceived and designed the study; KK, KT and SS created the questionnaire; TW and TY analyzed the data; TW and TY wrote the manuscript; TY, KT and SS contributed to critical revision of the manuscript; and SS had primary responsibility for the final content. All authors read and approved the final manuscript.

\section{Authors' information}

Thida Win is a doctoral student of the Department of Public Health and Occupational Medicine, Mie University Graduate School of Medicine, Toru Yamazaki is a lecturer of the Department of Public Health and Occupationa Medicine, Mie University Graduate School of Medicine and vice-director of Epidemiology Centre for Disease Control and Prevention, Mie University Hospital, Mie, Japan, Koji Kanda is a member of Japan International Cooperation Agency, Tokyo, Japan, Kazuo Tajima is a visiting professor of the Department of Public Health and Occupational Medicine, Mie University Graduate School of Medicine, and Shigeru Sokejima is a professor and head of the Department of Public Health and Occupational Medicine, Mie University Graduate School of Medicine and director of Epidemiology Centre for Disease Control and Prevention, Mie University Hospital, Mie, Japan.

\section{Ethics approval and consent to participate}

This study was approved by the Ethics Committee of the Medical Department of Mie University (approval number: 1268). Written informed consent was obtained from all participants. The study was conducted in accordance with the Helsinki Declaration.

\section{Consent for publication}

Not applicable. The published data does not contain details that could be traced to any individual participant.

\section{Competing interests}

The authors declare that they have no competing interests.

\section{Publisher's Note}

Springer Nature remains neutral with regard to jurisdictional claims in published maps and institutional affiliations.

\section{Author details}

'Department of Public Health and Occupational Medicine, Mie University Graduate School of Medicine, 2-174 Edobashi, Tsu-shi, Mie 514-8507, Japan. ${ }^{2}$ Epidemiology Centre for Disease Control and Prevention, Mie University Hospital, Tsu, Mie, Japan. ${ }^{3}$ Japan International Cooperation Agency, Tokyo, Japan.

Received: 7 April 2017 Accepted: 22 February 2018

Published online: 12 March 2018

\section{References}

1. SVS IK, Kim D. Social capital and health. New York: Springer; 2008.

2. Inaba Y. What's wrong with social capital? Critiques from social science. In: Kawachi I, Takao S, Subramanian SV, editors. Global Perspectives on Social Capital and Health. New York: Springer New York; 2013. p. 323-42.

3. Mohnen SM, Völker B, Flap H, Groenewegen PP. Health-related behavior as a mechanism behind the relationship between neighborhood social capital and individual health - a multilevel analysis. BMC Public Health. 2012;12(1):116.

4. Berkman LF, Kawachi I. Social epidemiology. Oxford: Oxford University Press; 2000.

5. Wilkinson R, Marmot M. Social determinants of health: the solid facts. 2nd ed; 2003.

6. Kawachi I, Berkman LF. Social ties and mental health. J Urban Health. 2001; 78(3):458-67.

7. Nieminen T, Prättälä R, Martelin T, Härkänen T, Hyyppä MT, Alanen E, Koskinen S. Social capital, health behaviours and health: a population-based associational study. BMC Public Health. 2013;13(1):613.

8. Toyosato T, Takakura M. Gender difference in the mediating effect of health-related behaviors on the relationship between neighborhood social capital and self-rated health among community dwelling people in a town of Okinawa. Ryukyu Med J. 2014;33(1-3):17-28.

9. Takahashi M, Tsutsumi A, Kurioka S, Inoue A, Shimazu A, Kosugi Y, Kawakami N. Occupational and socioeconomic differences in actigraphically measured sleep. J Sleep Res. 2014;23(4):458-62.

10. Bassett E, Moore S. Neighbourhood disadvantage, network capital and restless sleep: is the association moderated by gender in urban-dwelling adults? Soc Sci Med. 2014;108:185-93.

11. Vyncke V, Hardyns W, Peersman W, Pauwels L, Groenewegen P, Willems S. How equal is the relationship between individual social capital and psychological distress? A gendered analysis using cross-sectional data from Ghent (Belgium). BMC Public Health. 2014;14(1):960.

12. Addis $\mathrm{E}$, Joxhe M. Gender gaps in social capital: a theoretical interpretation of evidence from Italy. Fem Econ. 2017;23(2):146-71.

13. Norris P, Inglehart R. Gendering social capital: bowling in women's leagues? In: Gender and Social Capital. New York: Routledge; 2006. p. 73-98.

14. Ota H. Associations between individual-level social capital and self-rated health or depression among elderly men and women. Nihon Koshu Eisei Zasshi. 2014;61(2):71-85.

15. Stafford M, Cummins S, Macintyre S, Ellaway A, Marmot M. Gender differences in the associations between health and neighbourhood environment. Soc Sci Med. 2005;60(8):1681-92.

16. Ferlander S, Makinen $\mathrm{H}$. Social capital, gender and self-rated health. Evidence from the Moscow health survey 2004. Soc Sci Med. 2009;69(9):1323-32.

17. Leger D, Poursain B, Neubauer D, Uchiyama M. An international survey of sleeping problems in the general population. Curr Med Res Opin. 2008; 24(1):307-17.

18. Ikeda M, Kaneita Y. The newest epidemiology trend of insomnia. Nihon Rinsho. 2014;72(3):573-7.

19. Hirshkowitz M, Whiton K, Albert SM, Alessi C, Bruni O, DonCarlos L, Hazen N, Herman J, Katz ES, Kheirandish-Gozal L, et al. National Sleep Foundation's sleep time duration recommendations: methodology and results summary. Sleep Health. 2015;1(1):40-3.

20. OECD. Special focus: measuring leisure in OECD countries. Society at a Glance 2009: OECD Publishing; 2009.

21. Statistics Bureau, Ministry of Internal Affairs and Communications, Statistics Japan: Summary of Results (the 2011 Survey on Time Use and Leisure Activities). http://www.stat.go.jp/english/data/shakai/2011/k-gaiyou.htm. Accessed 10 Apr 2016.

22. Shen $X$, Wu Y, Zhang D. Nighttime sleep duration, 24-hour sleep duration and risk of all-cause mortality among adults: a meta-analysis of prospective cohort studies. Sci Rep. 2016;6:21480.

23. Shan Z, Ma H, Xie M, Yan P, Guo Y, Bao W, Rong Y, Jackson CL, Hu FB, Liu L. Sleep duration and risk of type 2 diabetes: a meta-analysis of prospective studies. Diabetes Care. 2015;38(3):529-37.

24. Gangwisch JE, Malaspina D, Boden-Albala B, Heymsfield SB. Inadequate sleep as a risk factor for obesity: analyses of the NHANES I. Sleep. 2005;28(10):1289-96.

25. Amagai Y, Ishikawa S, Gotoh T, Doi Y, Kayaba K, Nakamura Y, Kajii E. Sleep duration and mortality in Japan: the Jichi medical school cohort study. J Epidemiol. 2004;14(4):124-8.

26. Nakashima M, Morikawa Y, Sakurai M, Nakamura K, Miura K, Ishizaki M, Kido T, Naruse $Y$, Suwazono $Y$, Nakagawa H. Association between long working hours and sleep problems in white-collar workers. J Sleep Res. 2011;20(1 Pt 1):110-6.

27. Furihata R, Uchiyama M, Suzuki M, Konno C, Konno M, Takahashi S, Kaneita Y, Ohida T, Akahoshi T, Hashimoto S, et al. Association of short sleep duration and short time in bed with depression: a Japanese general population survey. Sleep and Biological Rhythms. 2015;13(2):136-45.

28. Nishiura C, Hashimoto H. A 4-year study of the association between short sleep duration and change in body mass index in Japanese male workers. J Epidemiol. 2010;20(5):385-90.

29. Kojima M, Wakai K, Kawamura T, Tamakoshi A, Aoki R, Lin Y, Nakayama T, Horibe H, Aoki N, Ohno Y. Sleep patterns and total mortality: a 12-year follow-up study in Japan. J Epidemiol. 2000;10(2):87-93.

30. Miller MA, Cappuccio FP. Inflammation, sleep, obesity and cardiovascular disease. Curr Vasc Pharmacol. 2007;5(2):93-102.

31. Miller MA. The role of sleep and sleep disorders in the development, diagnosis, and Management of Neurocognitive Disorders. Front Neurol. 2015;6:224.

32. Dettoni $\mathrm{J}$, Consolim-Colombo FM, Drager LF, Rubira MC, Souza SB, Irigoyen MC, Mostarda C, Borile S, Krieger EM, Moreno H Jr, et al. Cardiovascular effects of partial sleep deprivation in healthy volunteers. J Appl Physiol. 2012;113(2):232-6. 
33. Staner L. Sleep and anxiety disorders. Dialogues Clin Neurosci. 2003;5(3):249-58.

34. Paunio T, Korhonen T, Hublin C, Partinen M, Koskenvuo K, Koskenvuo M, Kaprio J. Poor sleep predicts symptoms of depression and disability retirement due to depression. J Affect Disord. 2015:172:381-9.

35. Sorensen G, Stoddard AM, Stoffel S, Buxton O, Sembajwe G, Hashimoto D, Dennerlein JT, Hopcia K. The role of the work context in multiple wellness outcomes for hospital patient care workers. J Occup Environ Med. 2011; 53(8):899-910.

36. Halperin D. Environmental noise and sleep disturbances: a threat to health? Sleep Sci. 2014;7(4):209-12

37. Dimitriou D, Le Cornu Knight F, Milton P. The role of environmental factors on sleep patterns and school performance in adolescents. Front Psychol. 2015;6:1717.

38. Mallampalli MP, Carter CL. Exploring sex and gender differences in sleep health: a Society for Women's Health Research report. J Women's Health (Larchmt). 2014;23(7):553-62.

39. Dai XJ, Gong HH, Wang YX, Zhou FQ, Min YJ, Zhao F, Wang SY, Liu BX, Xiao $X Z$. Gender differences in brain regional homogeneity of healthy subjects after normal sleep and after sleep deprivation: a resting-state fMRI study. Sleep Med. 2012;13(6):720-7.

40. Burgard SA. The needs of others: gender and sleep interruptions for caregivers. Social Forces. 2011;89(4):1189-215.

41. Okamoto K, Tanaka Y. Gender differences in the relationship between social support and subjective health among elderly persons in Japan. Prev Med. 2004;38(3):318-22.

42. Mallon L, Broman JE, Hetta J. High incidence of diabetes in men with sleep complaints or short sleep duration: a 12-year follow-up study of a middleaged population. Diabetes Care. 2005;28(11):2762-7.

43. Ham OK, Kim J, Lee BG, Choi E. Behavioral characteristics and cardiovascular disease risks associated with insomnia and sleep quality among middleaged women in South Korea. Res Nurs Health. 2017;40(3):206-17.

44. Nishide Y, Yamauchi N. Social capital and civic activities in Japan. Nonprofit Rev. 2005;5(1):13-28.

45. Lindstrom M, Moghaddassi M, Merlo J. Social capital and leisure time physical activity: a population based multilevel analysis in Malmö, Sweden. Epidemiol Community Health. 2003;57(1):23-8.

46. Harpham T, Grant E, Thomas E. Measuring social capital within health surveys: key issues. Health Policy Plan. 2002;17(1):106-11.

47. Hamano T, Fujisawa Y, Ishida Y, Subramanian SV, Kawachi I, Shiwaku K. Social capital and mental health in Japan: a multilevel analysis. PLoS One. 2010;5(10):e13214.

48. Åslund C, Nilsson KW. Social capital in relation to alcohol consumption, smoking, and illicit drug use among adolescents: a cross-sectional study in Sweden. Int J Equity Health. 2013;12(1):33.

49. Kripke DF, Garfinkel L, Wingard DL, Klauber MR, Marler MR. Mortality associated with sleep duration and insomnia. Arch Gen Psychiatry. 2002; 59(2):131-6.

50. Tamakoshi A, Ohno Y. Self-reported sleep duration as a predictor of allcause mortality: results from the JACC study, Japan. Sleep. 2004;27(1):51-4.

51. Heslop P, Smith GD, Metcalfe C, Macleod J, Hart C. Sleep duration and mortality: the effect of short or long sleep duration on cardiovascular and all-cause mortality in working men and women. Sleep Med. 2002;3(4):305-14.

52. Kim JH, Park EC, Cho WH, Park CY, Choi WJ, Chang HS. Association between total sleep duration and suicidal ideation among the Korean general adult population. Sleep. 2013;36(10):1563-72.

53. WHO physical activity. http://www.who.int/mediacentre/factsheets/fs385/en. Accessed 13 May 2016.

54. WHO BMI classification. http://www.euro.who.int/en/health-topics/diseaseprevention/nutrition/a-healthy-lifestyle/body-mass-index-bmi. Accessed 13 May 2016.

55. Allison PD. Logistic regression using SAS ${ }^{\bullet}$ t theory and application. 1st ed. Cary: SAS Institute Inc; 1999.

56. Kobayashi T, Suzuki E, Oksanen T, Kawachi I, Takao S. The bright side and dark side of workplace social capital: opposing effects of gender on overweight among Japanese employees. PLoS One. 2014;9(1):e88084.

57. Zhang J, Lam SP, Li SX, Tang NL, Yu MW, Li AM, Wing YK. Insomnia, sleep quality, pain, and somatic symptoms: sex differences and shared genetic components. Pain. 2012;153(3):666-73.

58. Imaizumi H, Takahashi A, Tanji N, Abe K, Sato Y, Anzai Y, Watanabe H, Ohira $\mathrm{H}$. The association between sleep duration and non-alcoholic fatty liver disease among Japanese men and women. Obes Facts. 2015;8(4):234-42.
59. Yuan YC: Multiple imputation for missing data: concepts and new development (version 9.0). SAS Inst Inc 2010:1-11.

60. Petersen MR, Deddens JA. A comparison of two methods for estimating prevalence ratios. BMC Med Res Methodol. 2008:8(1):9.

61. OECD Ageing and Employment Policies - Statistics on average effective age of retirement. http://www.oecd.org/els/emp/average-effective-age-ofretirement.htm. Accessed 5 Aug 2017.

62. Gilbert KL, Quinn SC, Goodman RM, Butler J, Wallace J. A meta-analysis of social capital and health: a case for needed research. J Health Psychol. 2013; 18(11):1385-99.

63. Sapp AL, Kawachi I, Sorensen G, LaMontagne AD, Subramanian SV. Does workplace social capital buffer the effects of job stress? A cross-sectional, multilevel analysis of cigarette smoking among U.S. manufacturing workers. J Occup Environ Med. 2010;52(7):740-50.

64. Varady DP. Desegregating the City: Ghettos, enclaves, and inequality: SUNY Press; 2006.

65. Boyas J, Wind LH. Employment-based social capital, job stress, and employee burnout: a public child welfare employee structural model. Child Youth Serv Rev. 2010;32(3):380-8.

66. Novak D, Kawachi I. Influence of different domains of social capital on psychological distress among Croatian high school students. Int J Ment Heal Syst. 2015;9(1):18.

67. Amendola F, Oliveira MA, Alvarenga MR. Influence of social support on the quality of life of family caregivers while caring for people with dependence. Rev Esc Enferm USP. 2011;45(4):884-9.

68. David-Barrett T, Rotkirch A, Carney J, Behncke Izquierdo I, Krems JA, Townley D, McDaniell E, Byrne-Smith A, Dunbar RIM. Women favour dyadic relationships, but men prefer clubs: cross-cultural evidence from social networking. PLoS One. 2015;10(3):e0118329.

69. Arber S, Meadows R. Unen sosiologia: hoiva, sukupuoli ja uniongelmat / sociology of sleep: caregiving, gender and sleep problems. Fin J Soc Med. 2011:48(2):100-13.

70. Morin $\mathrm{CM}$, Rodrique $\mathrm{S}$, Ivers $\mathrm{H}$. Role of stress, arousal, and coping skills in primary insomnia. Psychosom Med. 2003;65(2):259-67.

71. Hamilton NA, Nelson CA, Stevens N, Kitzman H. Sleep and psychological well-being. Soc Indic Res. 2007;82(1):147-63.

72. Braithwaite RL, Taylor SE, Treadwell HM. Health issues in the black community. 3rd ed: Jossey-bass; 2009.

73. Steptoe A, O'Donnell K, Marmot M, Wardle J. Positive affect, psychological well-being, and good sleep. J Psychosom Res. 2008;64(4):409-15.

74. Alamilla SG, Scott MA, Hughes DL. The relationship of individual and community level sociocultural and neighborhood factors to the mental health of ethnic groups in two large U.S. cities. J Community Psychol. 2016; 44(1):51-77.

75. Prins RG, Mohnen SM, van Lenthe FJ, Brug J, Oenema A. Are neighbourhood social capital and availability of sports facilities related to sports participation among Dutch adolescents? Int J Behav Nutr Phys Act. 2012;9(1):90

76. Lauderdale DS, Knutson KL, Yan LL, Liu K, Rathouz PJ. Self-reported and measured sleep duration: how similar are they? Epidemiology. 2008;19(6):838-45.

\section{Submit your next manuscript to BioMed Central and we will help you at every step:}

- We accept pre-submission inquiries

- Our selector tool helps you to find the most relevant journal

- We provide round the clock customer support

- Convenient online submission

- Thorough peer review

- Inclusion in PubMed and all major indexing services

- Maximum visibility for your research

Submit your manuscript at www.biomedcentral.com/submit 